\title{
Computerized Numerical Evaluation of Radiographic Images: The Destruction and Reduction of Bone Tissues in Periodontal Areas**
}

\author{
by \\ Shoichi ANDO*, Toshio NISHIOKA*, Koji SHINODA*, \\ Hiroyoshi YAMANO* and Mitsuhisa OZAWA*
}

\section{Introduction}

Published literature is available on the relations between the mineral content of human bones and its radiographic density[1,2]. Similar works have been carried out on the mandible in man [3-8]. The destruction and subsequent reduction of the alveolar bone under the invading influence of periapicosis or paradentpathia is well known but, so far, no definite quantitative method of evaluation has been established to determine an exact degree of destruction or reduction that takes place.

It is generally accepted that when the human mandible is artificially decalcified within experimental processes in vitro, about $50 \%$ decalcification of bone minerals brings about 1.8 photographic density and gives an impression of lost structure[8]. This means that there will no longer exist a bone substance from a clinical point of view. In dental practice, this kind of phenomenon is referred to as the bone resorption or destruction and it is usually interpreted as having no supporting bone structure of the tooth. The decision for dental extraction is often determined by this fact.

However, it has been our experience to find cases in which the bone structure is completely lost, on the one hand, and those cases in which mineral contents are much reduced while suffering from no pathologic change in the bone itself, on the other. In the latter case, if we could provide an adequate treatment the supporting structure would be restored to the teeth involved. Radiographs taken of the latter cases have hitherto provided us with diagnostic information and their interpretation (and subsequent establishment of treatment planning) is not carefully control from dentist to dentist.

It is to be admitted, of course, that for a proper and effective diagnosis to be given a radiogram should contain abundant diagnostic information presented in a clearly enough fashion but, at the same time, it will need be interpreted by sound fundamental knowledge on the part of an attending dentist. In other words, a better diagnostic result will be possible when it is based on objective information as much as possible.

In a previous report, the authors described a few basic techniques of interpreting relative densities of the radiograms by the use of an electronic computer and microphotometric scanning for better and more objective diagnosis [9].

\footnotetext{
*安藤正一, 西岡敏雄, 篠田宏司, 山野博可, 尾澤光久, Department of Radiology, Nihon Univ, School of Dentistry, Surugadai, Chiyoda-ku, Tokyo.

**The gist of the present study has exhibited in the 28th general meeting of Nippon Societas Radiologica in 1969, held in Yanago City.
} 
This paper relates to our successful efforts in the numerical evaluation by successive stages of healing processes of a pathologic behavior under clinical conditions, in which change in the differences was indicated by the subtraction method.

\section{Materials}

By way of our study material, use was made of a series of standard-intraoral radiograms. Case one consisted of radiograms taken of successive stages of periapicosis which was caused by the destruction of a bone in the size of a large bean in the periapical region of $\lfloor 1$ and which was improved by a subsequent treatment. Case two compared radiographic images of a destroyed peripheral alveolar ridge by the presence of paradentpathia, taken right after a surgical operation, and of healthy bone structures that were restored as a result of various postoperative therapeutic measures. Since these two series of radiograms were taken by the standardized technique, they gave almost similar geometrical patterns.

\section{Method}

\subsection{Two different methods.}

This study followed much of our basic techniques previously reported and it differed in the following two important methods. For one thing, speed of microphotometric scanning was increased and, as a result, it was possible to scan an entire surface of the radiogram within 10 minutes at $64 \mathrm{~mm} / \mathrm{m}$. In the second place, as we used monocolor 8 markings in our previous investigation, a maximum of 9 levels was possible including one non-marked portion. However, here we made use of 4 different color schemes and it was possible to obtain a combination of 32 levels for the indication of relative densities of each matrix on the radiographic image.

3.2 Establishment of sampling points and quantification of relative densities in these spots.

For scanning purposes, 5400 sampling points were provided for the anterior region of dental films: 90 points at intervals of $0.3 \mathrm{~mm}$ on an $\mathrm{x}$-axis $(\mathrm{m})$ and 60 points at intervals of $0.5 \mathrm{~mm}$ on a $\mathrm{y}$-axis, where $\mathrm{Xi}_{1-60}$ and $\mathrm{Xj}_{1-90}$ and $\mathrm{m} \times \mathrm{n}$ produced 5400 . Similarly, 5600 points ( 112 for $\mathrm{x}$ - and 50 for $\mathrm{y}$-axis respectively) were provided for the posterior region scanning.

3.3 Processing of quantified data.

The relative densities scanned at the sampling points were numerically converted in a range of 0 to 255 and were sequentially filed on a computer magnetic core memory. For observational purposes, they were punched on 6-unit paper tape with binary notation and the same sets of data were automatically printed out on a record sheet. Finally, significant data were classified by means of levels already provided and means and standard deviations were computed for their statistical treatment. When found necessary, Fourier transformation and weighted means were applied. All the sampling points were in this way clusterized into 32 levels for each different color scheme.

3.4 Symbols and color display for the relative densities.

Our 9-level notation, which was employed previously in connection with the 
radiographic images of the teeth and alveolar bony region, was not sufficiently fine to analyze delicate quantitative change in the alveolar bone.

Our present application of 32-level notation made it possible to discern in terms of relative densities the amount of reduction or disappearance of alveolar ridges, enamel, dentin area, pulpal cavity, periodontal space, canal filling, filling material, post-dowel of a prosthetic crown and its base metal, if any, etc.

3.5 Subtraction of difference in the relative densities.

When the radiographical figures taken pior to, during and after a treatment follow similar geometrical patterns, it follows that one can study the presence or absence of difference in the relative densities of common spots by overlaying one on the other. In other words, we examined any discrepancy of the relative densities.

\section{Healing Processes of Cases One and Two}

Case one

\section{4-year old girl, case of periapicosis.}

Necrosis of the pulp beneath a silicate cement filling on the mesial proximal surface of $\lfloor 1$ led to a bean-size abscess formation on the apical portions of $\lfloor 1$ and $\lfloor 2$ including the interalveolar septa, producing a suppurative destruction of the bone involved. Her pulpal cavity was opened and the necrotic pulp tissues and a large quantity of pus were removed through the root canal and it was given a drain (Fig. 1, A and B). Following the stoppage of pus discharge or exudate, an antibiotic agent was locally administered via root canal. After 3 months, that part of bone which was a disappearing bone trabecula came to be restored (Fig. 2, A and B). The therapeutic measure was continued over fixed intervals and after 12 months the genesis of bone structure was quite apparent (Fig. 3, A and B).

\section{Case two}

\section{3-year old woman, case of paradentpathia.}

A fairly advanced degree of paradentpathia was observed all over the teeth, being most pronounced on the upper left posteriors. A series of $\mid 4567$ was quite shaky and the patient complained of a pain under the occlusal load. At the time of her initial consultation, it looked like Fig. 4, A and B. She was administered a basic paradentpathic treatment as local therapeutic measures on all the teeth and their occlusal equilibrations. A flap operation was given to $\lcm{4567}$ region. Figs. 5, A and B were taken immediately postoperatively. A temporary fixation of the teeth was combined with various treatments. After these procedures, the teeth could be tightly fixed in their

Explanation of the leveling on relative densities.

The 32 levels were coded as follows:

\begin{tabular}{|c|c|c|c|c|c|c|c|c|c|}
\hline & $\begin{array}{l}* * * * \\
* * * *\end{array}$ & $\begin{array}{l}* * * \\
* * *\end{array}$ & $* *$ & $* * *$ & $* *$ & * & + & - & Blank \\
\hline & $0-28$ & 29 & $37-44$ & $45-52$ & $53-60$ & $61-67$ & $68-75$ & 76 & \\
\hline Green & $77-83$ & $84-91$ & $92-99$ & $100-107$ & $108-115$ & $116-123$ & $124-130$ & 131 & \\
\hline Violet & $132-138$ & 139-146 & $147-154$ & $155-162$ & $163-170$ & $171-178$ & $179-186$ & 187 & \\
\hline Pink & $188-193$ & 194-201 & $202-209$ & $210-217$ & $218-225$ & $226-233$ & $234-241$ & $242-248$ & 255) \\
\hline
\end{tabular}



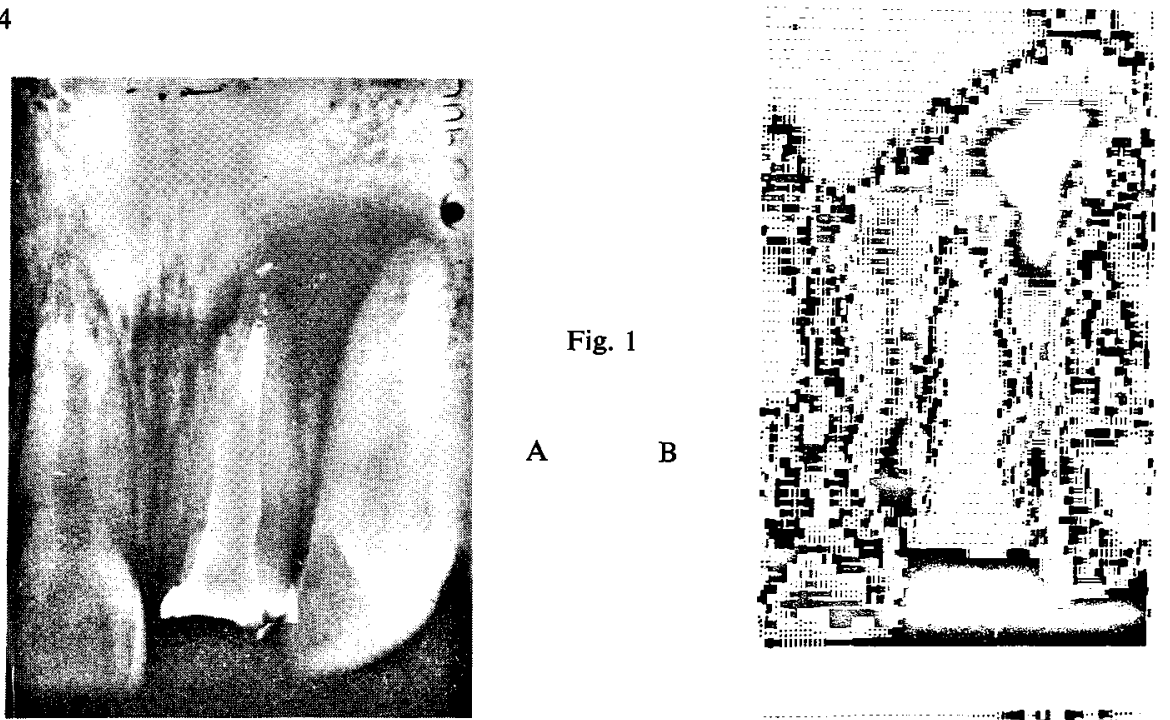

Fig. 1

A

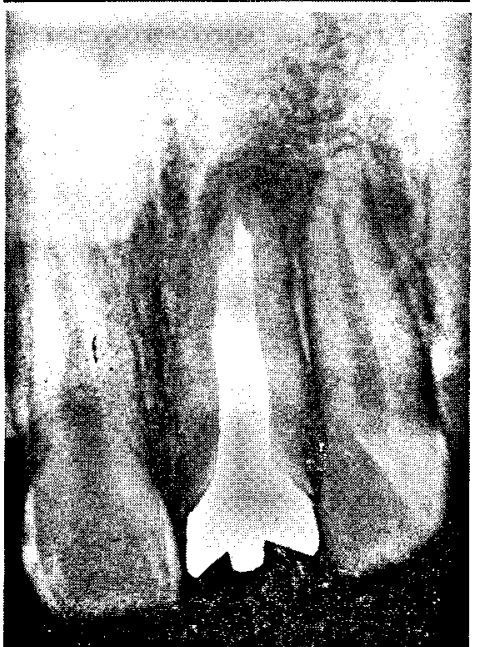

A
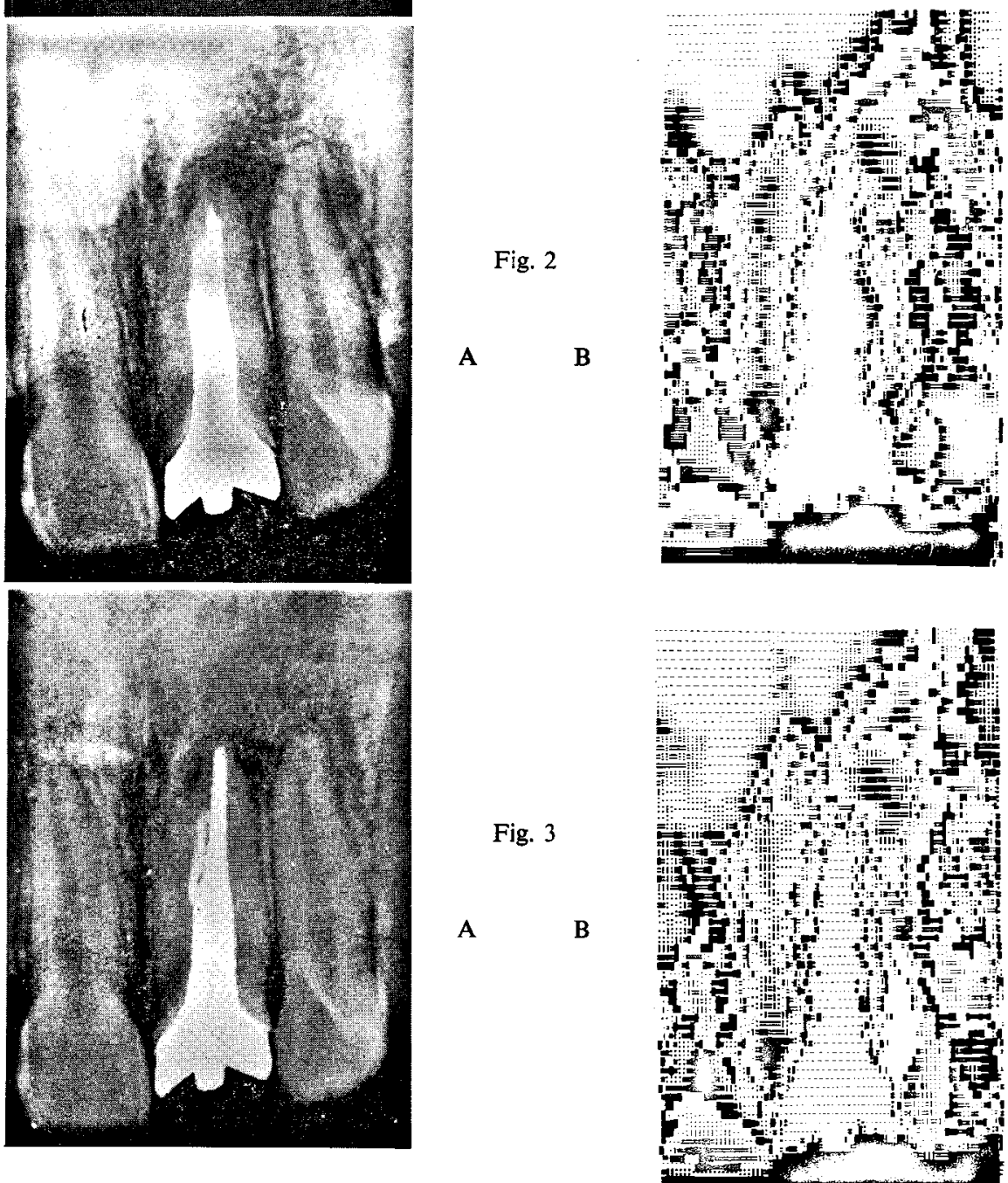
sockets and the patient stopped complaining of an occlusal pain. After 12 months since her initial consultation, a fairly large area of the alveolar bones and compact bone structure appeared on the peripheral regions observable as linea alba (Fig. 6, A and B).

As has been described above, our present method applied here enabled us to determine minutely the destruction of bone structures in the cases of periapicosis and paradentpathia and their restorations subequently brought about treatments.

It is believed that this method will replace individual interpretative differences of dentists by an objective evaluation and, further, differences in the relative densities can be compared directly between a set of radiograms.

\section{Discussion}

In the present study, the authors succeeded in determining on radiograms the efficacy of healing processes on the cases of periapicosis and paradentpathia, leading to the gradual genesis of bones in the destroyed areas. This was accomplished by the establishment of 5400 to 5600 sampling points covering an entire surface of the radiogram, by the quantification of their relative densities and by the display of 32-level color notation. Thus we could bring an element of numerical evaluation into the field where the interpretation was largely subjective. However, we believe that for a more precise diagnostic quantification some kind of three-dimensional technique will be more effective than a two-dimensional one of $x$-axis and y-axis plotting. McIntyre and his associates [10] succeeded in their three-dimensional cumputer readout in connection with their study of colloidal ${ }^{198} \mathrm{Au}$ distributed in the normal state and metastatic tumors and ${ }^{131}$ Iodine in the thyroid tumor, in which they used three axes of $x, y$ and $z$ for the quantification of radiographic relative densities. Since the internal organs are invisible from outside, there is no doubt that this kind of three-dimensional approach is a very effective diagnostic aid. However, for the diagnosis of pathologic changes in the teeth and alveolar bones which lend themselves for direct radiographic observation a method here presented by authors is felt to be much more effective for their diagnostic information to be precisely analyzed.

\section{Conclusions}

As a result of a conjoint application of the microphotometry and electronic computer, the authors devised a new method by means of which the dental radiographic images can be accurately quantified. This method makes the following operations possible.

1. Volumetric changes in the teeth and alveolar bone structures can be expressed quantitatively.

2. The radiographic relative densities can be clusterized in 32 levels by a combination of 8 symbols and 4 color schemes, by establishing a numerical range of 0 to 255 .

3. By the use of these notations, the subtraction enables differences in common portions of the radiographic relative densities to be grasped and expressed quantitatively.

4. It is also possible to obtain matrices, difference in the number of sampling points or area ratios for those different relative densities. 

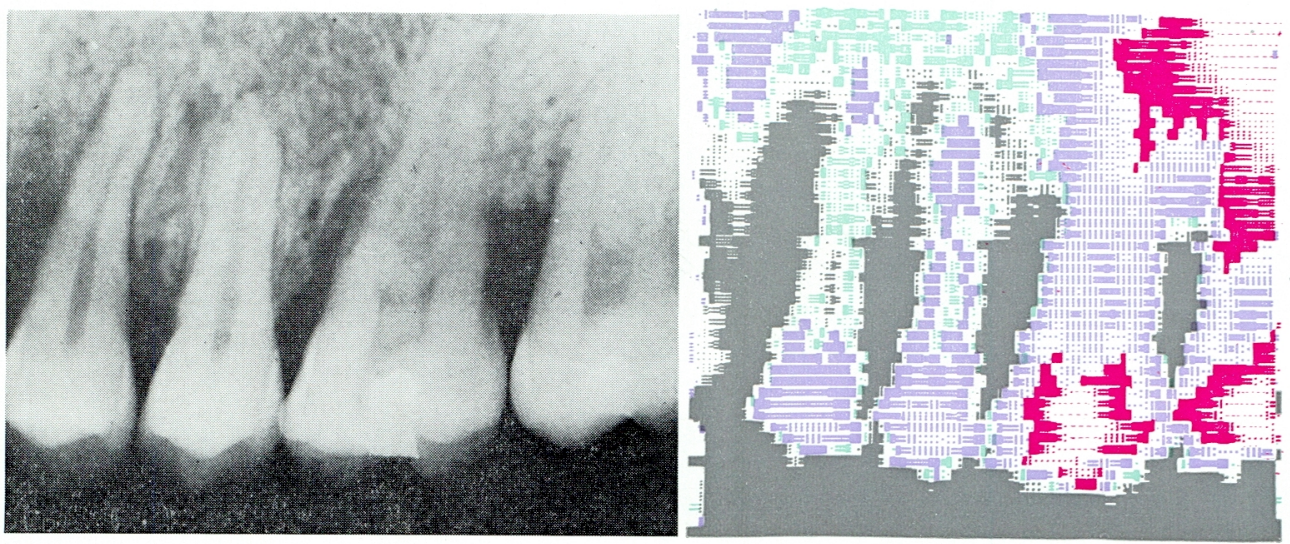

A

Fig. 4

B

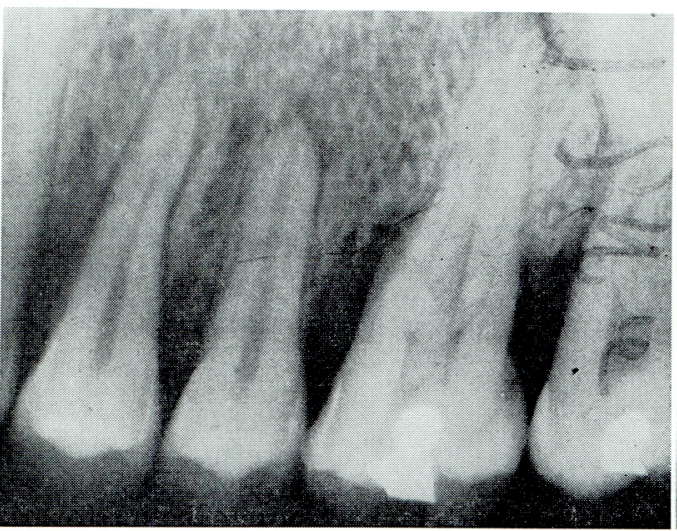

A

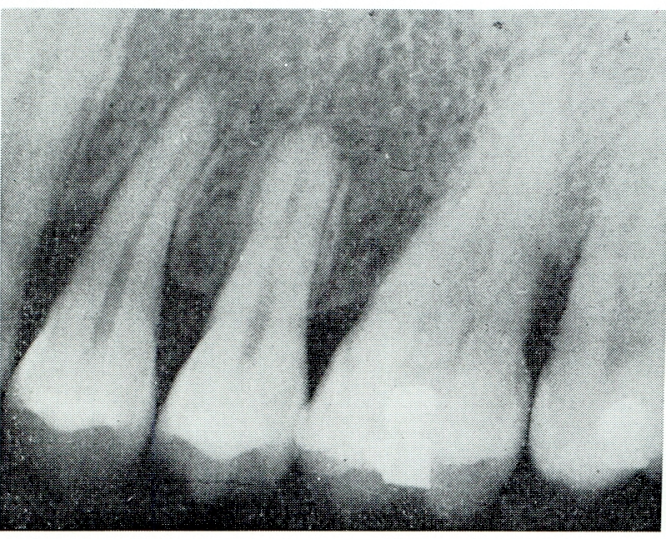

A

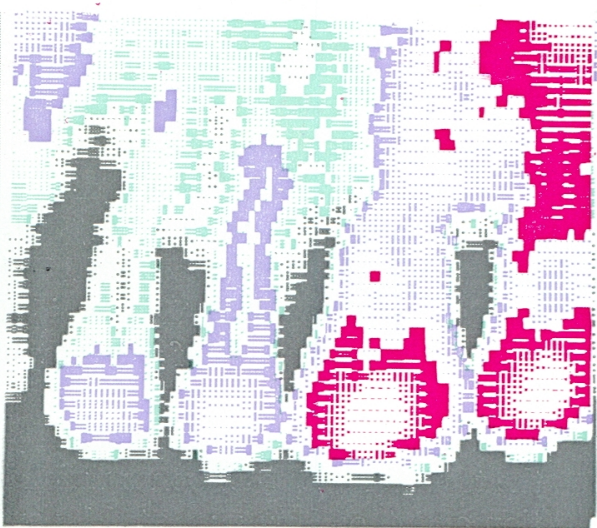

Fig. 5

B

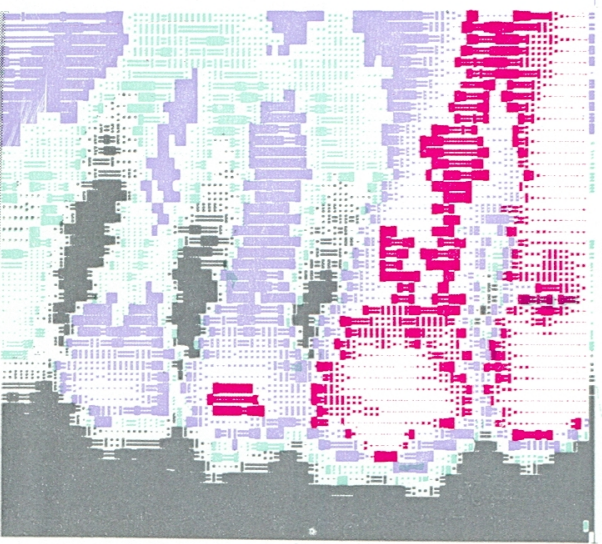

Fig. 6

B 


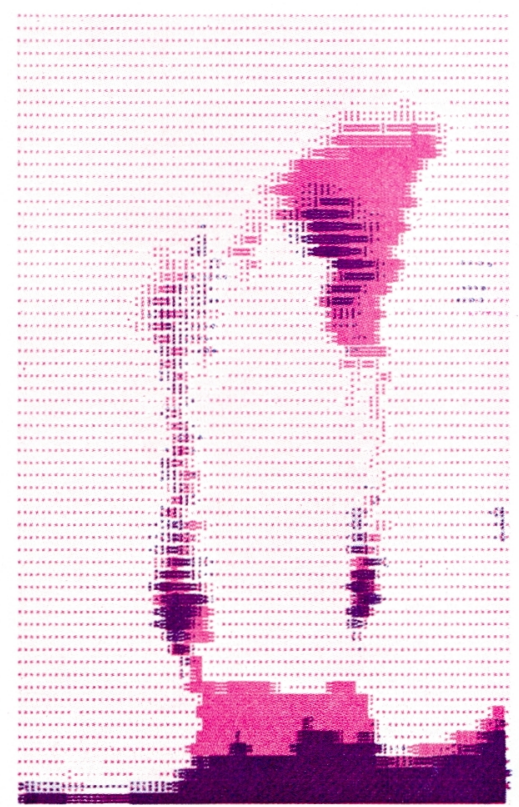

Fig. 7

Subtraction display: To subtract Fig. 3 (violet) from Fig. 1 (pink)

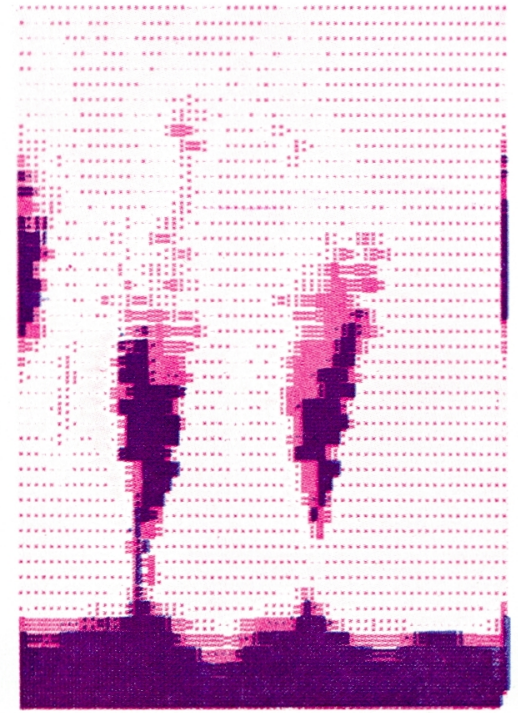

Fig. 8

Subtraction display: To subtract Fig. 6 (violet) from Fig. 4 (pink)

5. We have to wait for the future to determine whether a three-dimensional approach will be more effective than a two-dimensional one, at least, for this kind of diagnostic information processing.

\section{References}

[1] Trotter, M., Broman, G. E. and Peterson, R. R.: Densities of bones of white and black skeletons, J, Bone and Joint Surg., 42-A (1960), pp. 50-58.

[2] Oкичама, T.: A study of the quantitative analysis on the mineral contents of bones by X-rays, Nippon Acta Radiologica, 25:775-790, 1965.

[3] OmNell, K.: Quantitative roentgenologic studies on the changes in mineral content of bone in vivo, Acta Radiologica, Suppl. \#148:5025, 71-81, 1957.

[4] Tamisalo, E. H. and Kiminki, A.: Density and mineral content of human mandibles, Acta Odont. Scand., (in prep).

[5] Tamisalo, E. H. and Kiminki, A.: Cortical ratio as an indicator of the mineral content of human mandibular bones, Acta Odont. Scand., (in prep.).

[6] Tamisalo, E. H. and Tamisalo, R.: Correlation between density of the alveolar trabecular pattern and the actual mineral content of human mandibles, Acta Odont. Scand., (in press)

[7] Uotila, E. and VisapäÄ, A.: Evaluation of mineral content of bone in vitro: Quantitative analysis of calcium and phosphorus by X-ray fluorescence, Odont. T. (in prep.).

[8] Wakamatsu, H.: On the relation between the amount of experimental decalcification of human mandibles and the density of their radiograms, Nihon Univ. Dent. J., 43, 1963.

[9] Ando, S. et al.: Computer analysis of radiographic images, J. Nihon Univ. Sch. Dent., 10:65-70, 1968.

[10] McIntyre, W. J., Christie, J. H. and Curtis, G. S.: Three dimensional computer read-out of radioisotope scan data, Radiology, 90:22-26, 1968. 